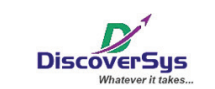

Published by DiscoverSys

\section{Employment and Education as Risk Factors of Cataract Incidence on Patients Treated in Eye Health Centre Mataram City West Nusa Tenggara}

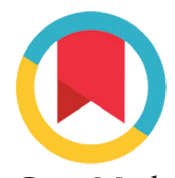

CrossMark
Ni Nyoman Santi Tri Ulandari, ${ }^{1,4 *}$ Putu Ayu Swandewi Astuti, ${ }^{2}$ I Nyoman Adiputra ${ }^{3}$

\section{ABSTRACT}

Background and purpose: The purpose of the study was to determine the risk factors of employment, education and other risk factors on the occurrence of cataracts in patients seeking treatment at Eye Health Center in the City of Mataram, West Nusa Tenggara.

Methods: The study was a case-control with a sample of cases and controls, respectively amounted to 40 (1: 1). The dependent variable was patients with cataract and independent variables were: education, employment, income, diabetes mellitus, history of cataracts, smoking behavior, and exposure to smoke and sun exposure. Data were collected by means of interviews using questionnaires and tracking documents of patients' medical records. Data analysis was performed using univariate, bivariate to determine the comparability between cases and controls and to see the crude of OR. Multivariate analyses were performed to determine the adjusted $O R$.

Results: Four variables were found to be risk factors to the occurrence of cataracts: education, income, occupation and exposure to sunlight with each crude OR of 10.50 (95\% Cl: 3.39 to 32.52$) ; 6.23$ (95\% Cl: 2.35 to 16.51), 10.52 ( $95 \%$ Cl: 3.56 to 31.12 ); and 3.11 (95\% Cl: 1.25 to 7.78 ). While diabetes mellitus, family history of cataracts, smoking behavior and exposure to smoke was not statistically proven as a risk factor for cataracts. The multivariate analysis showed that most risk factors played a role in the occurrence of cataract was employment with $\mathrm{OR}=9.81$ (95\% Cl: 1.85 to 52.02 ) and education with $\mathrm{OR}=6.53$ (95\% Cl: 1.42 to 29.92$)$. Conclusion: Employment and education were significant risk factors to the occurrence of cataracts in patients who visited the Eye Health Center in the City of Mataram, West Nusa Tenggara.

\title{
Pekerjaan dan Pendidikan sebagai Faktor Risiko Kejadian Katarak pada Pasien yang Berobat di Balai Kesehatan Mata Masyarakat Kota Mataram Nusa Tenggara Barat
}

\section{ABSTRAK}

'Public Health Postgraduate Program Udayana University, ${ }^{2}$ School of Public Health Faculty of Medicine Udayana University, ${ }^{3}$ Physiology Department Faculty of Medicine Udayana University, ${ }^{4}$ College of Health Sciences (STIKES) Mataram City

\section{*Correspondence to:}

Ni Nyoman Santi Tri Ulandari, Public Health Postgraduate Program Udayana University, College of Health Sciences (STIKES) Mataram City

santhi_rastika@yahoo.com
Latar belakang dan tujuan: Tujuan penelitian adalah untuk mengetahui faktor risiko pekerjaan, pendidikan dan faktor risiko lainnya terhadap terjadinya katarak pada pasien yang berobat di Balai Kesehatan Mata Masyarakat di Kota Mataram, Nusa Tenggara Barat. Metode: Desain penelitian adalah kasus-kontrol dengan jumlah sampel kasus dan kontrol masing-masing sebanyak 40 (1:1). Variabel terikat adalah pasien dengan katarak dan variabel bebas adalah: pendidikan, pekerjaan, pendapatan, diabetes melitus, riwayat penyakit katarak, perilaku merokok, paparan asap dan paparan sinar matahari. Data dikumpulkan dengan cara wawancara menggunakan kuesioner dan penelusuran dokumen catatan medis pasien. Analisis data dilakukan secara univariat, bivariat untuk mengetahui komparabilitas antara kelompok kasus dan kontrol dan untuk melihat crude OR. Analisis multivariat dilakukan untuk mengetahui adjusted $O R$.
Hasil: Penelitian menemukan empat variabel yang menjadi faktor risiko kejadian katarak yaitu pendidikan, pendapatan, pekerjaan dan paparan sinar matahari dengan crude OR masing-masing sebesar 10,50 (95\%Cl: 3,39-32,52); 6,23 (95\%Cl: 2,35-16,51), 10,52 (95\%Cl: 3,56-31,12); dan 3,11 (95\%(l: 1,25-7,78). Sedangkan diabetes melitus, riwayat keluarga dengan penyakit katarak, perilaku merokok dan paparan asap secara statistik tidak dijumpai sebagai faktor risiko katarak. Pada analisis multivariat diperoleh bahwa faktor risiko yang paling berperan adalah pekerjaan dengan $\mathrm{OR}=9,81(95 \% \mathrm{Cl}$ : 1,85$52,02)$ dan pendidikan dengan $\mathrm{OR}=6,53$ (95\% Cl: 1,42-29,92).

Simpulan: Pekerjaan dan pendidikan merupakan faktor risiko yang signifikan terhadap terjadinya katarak pada pasien yang berkunjung di Balai Kesehatan Mata Masyarakat di Kota Mataram, Nusa Tenggara Barat. 
Kata kunci: katarak, kasus-kontrol, BKMM-NTB, faktor risiko

Kutip artikel ini: Ulandari, N.N.S.T., Astuti, P.A.S., Adiputra, I.N. 2014. Pekerjaan dan Pendidikan sebagai Faktor Risiko Kejadian Katarak pada Pasien yang Berobat di Balai Kesehatan Mata Masyarakat Kota Mataram Nusa Tenggara Barat. Public Health and Preventive Medicine Archive 2(2): 121-125. D0I:10.15562/phpma.v2i2.137

\section{PENDAHULUAN}

Katarak terjadi akibat kekeruhan pada lensa mata yang mengakibatkan terganggunya cahaya masuk ke dalam bola mata, sehingga penglihatan menjadi kabur dan lama kelamaan dapat menyebabkan kebutaan. ${ }^{1}$ Indonesia adalah salah satu negara yang memiliki prevalensi katarak cukup tinggi dimana secara nasional proporsi penduduk umur 30 tahun yang didiagnosis menderita katarak pada tahun 2007 sebesar $1,8 \%^{2}$ sedangkan untuk daerah Nusa Tenggara Barat sebesar 2,0\%. ${ }^{3}$ Secara nasional prevalensi kebutaan pada tahun 2007 karena katarak dijumpai sebesar $0,9 \%{ }^{2}$ dan turun menjadi $0,4 \%$ pada tahun 2013, ${ }^{4}$ sedangkan untuk NTB proporsi penderita katarak yang menjadi buta sesuai dengan hasil Riset Kesehatan Dasar (Riskesdas) 2007 adalah sebesar $1,1 \% .^{3}$

Banyak faktor yang ditemukan berhubungan dengan penyakit katarak, diantaranya adalah pekerjaan dan pendidikan. Pekerjaan yang berisiko untuk terjadinya katarak adalah pekerjaan yang dilakukan lebih banyak di luar gedung (outdoor), sedangkan pendidikan berkaitan dengan tingkat pekerjaan yang dimiliki seseorang. Berdasarkan Riskesdas 2007 terlihat bahwa prevalensi katarak dijumpai cukup tinggi pada petani/nelayan/buruh yaitu sebesar $17,8 \%$ dan pada pekerjaan lain sebesar $8,4 \%$. Sebesar 22,0\% pada kelompok lama pendidikan $\leq 6$ tahun, dan pada lama pendidikan $>12$ tahun sekitar $8,8 \%$. $^{2}$ Tujuan penelitian ini adalah untuk mengetahui faktor risiko pekerjaan, pendidikan dan faktor risiko lainnya terhadap terjadinya katarak pada pasien yang berobat di Balai Kesehatan Masyarakat Nusa Tenggara Barat.

\section{METODE}

Rancangan penelitian adalah kasus-kontrol dengan jumlah sampel kasus dan kontrol masing-masing sebanyak 40 (1:1) yang dipilih secara consecutive dari pasien katarak dan tidak katarak yang berobat di Balai Kesehatan Mata Masyarakat (BKMM) Kota Mataram NTB, dan dimiripkan dalam hal umur dan jenis kelamin. Kriteria katarak dan tidak katarak mengacu pada diagnosis yang telah ditetapkan oleh BKMM Kota Mataram dan berumur sekurangkurangnya 35 tahun. Jumlah sampel dihitung dengan mengacu pada pedoman $\mathrm{WHO}^{5}$ dengan parameter: alpha $=0,05$; power 95 ; estimasi $\mathrm{OR}$ untuk variabel pendidikan $=4,2,{ }^{6}$ data tentang karakteristik kasus dan kontrol serta informasi tentang faktor risiko (diabetes melitus, riwayat keluarga yang menderita katarak, perilaku merokok, pendapatan, pendidikan, pekerjaan, paparan asap dan paparan sinar matahari), dikumpulkan dengan cara wawancara tatap muka bertempat di BKMM Kota Mataram, dengan menggunakan kuesioner yang telah dipersiapkan. Informasi tentang diabetes melitus diperoleh dengan cara wawancara pada kasus dan kontrol berdasarkan hasil pemeriksaan yang dilakukan oleh BKMM. Pengumpulan data dilaksanakan pada Bulan Maret sampai April 2014 oleh peneliti dan dibantu oleh satu orang perawat yang telah dilatih. Pengelompokan data tentang faktor risiko adalah: diabetes melitus dikelompokkan menjadi diabetes melitus dan tidak diabetes mellitus; riwayat penyakit katarak dikelompokkan menjadi ada riwayat penyakit katarak dan tidak ada riwayat penyakit katarak; perilaku merokok dikelompokkan berdasarkan merokok dan tidak merokok; pendidikan berdasarkan tingkat pendidikan yang ditamatkan oleh responden dikelompokkan menjadi pendidikan rendah (tidak sekolah-lulus SMP) dan pendidikan tinggi (lulus SMA-sarjana); pendapatan dikelompokkan menjadi pendapatan rendah $<1.200 .000$ dan tinggi $\geq 1.200 .000$ berdasarkan upah minimum regional NTB; pekerjaan dikelompokkan menjadi pekerjaan di luar gedung $\geq 4$ jam dan pekerjaan di luar gedung $<4$ jam; paparan asap dikelompokkan menjadi terpapar dan tidak terpapar; dan terpapar sinar matahari dikelompokkan menjadi terpapar sinar matahari $\geq 4$ jam dan $<4$ jam.

Analisis data secara univariat untuk melihat frekuensi dari masing-masing variabel, analisis bivariat untuk melihat komparibilitas antara kelompok kasus dan kelompok kontrol, serta mendapatkan nilai crude OR dengan menggunakan Stata SE 12.1. Sedangkan analisis multivariat dilakukan dengan regresi logistik metode enter untuk mendapatkan nilai adjusted OR. Penelitian ini sudah mendapatkan kelaikan etik dari Komisi Etik Fakultas Kedokteran Universitas Mataram.

\section{HASIL}

Semua responden kasus dan kontrol yang memenuhi syarat penelitian bersedia untuk diwawancarai. Karakteristik responden sebagaian 
besar tidak memiliki penyakit diabetes melitus (68; 85,0\%), tidak ada riwayat penyakit katarak pada keluarga $(64 ; 80,0 \%)$, pendidikan rendah (51; $63,8 \%)$, tidak merokok (47; 58,8\%), berpendapatan rendah $(43 ; 53,8 \%)$, pekerjaan $\geq 4$ jam di luar gedung $(48 ; 60,0 \%)$, terpapar asap $(67 ; 83,8 \%)$ dan terpapar sinar matahari $<4$ jam (43; 53,7\%). Sedangkan untuk karakteristik antara kasus dan kontrol berdasarkan umur dan jenis kelamin sudah dimiripkan dan disajikan pada Tabel 1.
Hasil analisis bivariat seperti disajikan pada Tabel 2 menunjukkan bahwa diabetes mellitus meningkatkan risiko katarak sebesar 2,25 kali $(\mathrm{OR}=2,25 ; 95 \% \mathrm{CI}: 0,62-8,18)$; riwayat penyakit katarak pada keluarga sebesar 1,37 kali $(\mathrm{OR}=1,37$; 95\%CI: 0,45-4,12); perilaku merokok sebesar 0,90 kali (OR=0,90; 95\%CI: 0,37-2,12); paparan asap sebesar 2,61 kali (OR=2,61; 95\%CI: 0,73-9,32); namun semua variabel tersebut secara statistik tidak bermakna karena batas bawah CI kurang

Tabel 1 Karakteristik umur dan jenis kelamin pada kelompok kasus dan kontrol

\begin{tabular}{|c|c|c|c|c|c|}
\hline \multirow[b]{2}{*}{ Variabel } & \multicolumn{2}{|c|}{ Kasus } & \multicolumn{2}{|c|}{ Kontrol } & \multirow[b]{2}{*}{ Nilai p } \\
\hline & $\mathbf{n}$ & $\%$ & $\mathbf{n}$ & $\%$ & \\
\hline Umur & & & & & 1,000 \\
\hline$\geq 40$ tahun & 37 & 92,5 & 37 & 92,5 & \\
\hline$<40$ tahun & 3 & 7,5 & 3 & 7,5 & \\
\hline Jenis kelamin & & & & & 1,000 \\
\hline Laki-laki & 17 & 42,5 & 17 & 42,5 & \\
\hline Perempuan & 23 & 57,5 & 23 & 57,5 & \\
\hline
\end{tabular}

Tabel 2 Crude OR faktor risiko katarak

\begin{tabular}{|c|c|c|c|c|c|}
\hline Faktor risiko & $\begin{array}{c}\text { Kasus } \\
(\%)\end{array}$ & $\begin{array}{c}\text { Kontrol } \\
(\%)\end{array}$ & Crude OR & $95 \% \mathrm{Cl}$ & Nilai p \\
\hline \multicolumn{6}{|l|}{ Diabetes melitus } \\
\hline Diabetes melitus & $8(20,0)$ & $4(10,0)$ & 2,25 & $0,62-8,18$ & 0,21 \\
\hline Tidak diabetes melitus & $32(80,0)$ & $36(90,0)$ & & & \\
\hline \multicolumn{6}{|l|}{ Riwayat katarak pada keluarga } \\
\hline Ada riwayat & $9(22,5)$ & $7(17,5)$ & 1,37 & $0,45-4,12$ & 0,58 \\
\hline Tidak ada riwayat & $31(77,5)$ & $33(82,5)$ & & & \\
\hline \multicolumn{6}{|l|}{ Perilaku merokok } \\
\hline Merokok & $16(40,0)$ & $17(42,5)$ & 0,90 & $0,37-2,12$ & 0,82 \\
\hline Tidak merokok (tidak/mantan) & $24(60,0)$ & $23(57,5)$ & & & \\
\hline \multicolumn{6}{|l|}{ Pendidikan } \\
\hline Pendidikan rendah (tidak sekolah-SMP) & $35(87,5)$ & $16(40,0)$ & 10,50 & $3,39-32,52$ & $<0,0001$ \\
\hline Pendidikan tinggi (SMA-sarjana) & $5(12,5)$ & $24(60,0)$ & & & \\
\hline \multicolumn{6}{|l|}{ Pendapatan } \\
\hline Pendapatan rendah $(<1.200 .000)$ & $30(75,0)$ & $13(32,5)$ & 6,23 & $2,35-16,51$ & $<0,0001$ \\
\hline Pendapatan tinggi $(\geq 1.200 .000)$ & $10(25,0)$ & $27(67,5)$ & & & \\
\hline \multicolumn{6}{|l|}{ Pekerjaan } \\
\hline$\geq 4$ jam di luar gedung & $34(85,0)$ & $14(35,0)$ & 10,52 & $3,56-31,12$ & $<0,0001$ \\
\hline$<4$ jam di luar gedung & $6(15,0)$ & $26(65,0)$ & & & \\
\hline \multicolumn{6}{|l|}{ Paparan asap } \\
\hline Terpapar & $36(90,0)$ & $31(77,5)$ & 2,61 & $0,73-9,32$ & 0,13 \\
\hline Tidak terpapar & $4(10,0)$ & $9(22,5)$ & & & \\
\hline \multicolumn{6}{|l|}{ Paparan sinar matahari } \\
\hline$\geq 4$ jam & $24(60,0)$ & $13(32,5)$ & 3,11 & $1,25-7,78$ & 0,01 \\
\hline$<4$ jam & $16(40,0)$ & $27(67,5)$ & & & \\
\hline
\end{tabular}


Tabel 3 Adjusted OR faktor risiko katarak

\begin{tabular}{lcccc}
\hline & & \multicolumn{2}{c}{$\mathbf{9 5 \% C l}$} & \multirow{2}{*}{ Nilai p } \\
\cline { 3 - 4 } Faktor risiko & Adjusted OR & Batas bawah & Batas atas & Nilan \\
\hline Pekerjaan & 9,81 & 1,85 & 52,01 & 0,007 \\
Pendidikan & 6,53 & 1,42 & 29,92 & 0,016 \\
\hline
\end{tabular}

dari satu. Sedangkan variabel yang secara statistik bermakna meningkatkan risiko terjadinya katarak yaitu pendidikan sebesar 10,50 kali $(\mathrm{OR}=10,50$; 95\%CI: 3,39-32,52) pendapatan sebesar 6,23 kali $(\mathrm{OR}=6,23$; 95\%CI: 2,35-16,51), pekerjaan sebesar 10,52 kali (OR=10,52; 95\%CI: 3,56-31,12) dan paparan sinar matahari sebesar 3,11 kali $(\mathrm{OR}=3,11$; 95\%CI: 1,25-7,78).

Pada penelitian ini, analisis multivariat dilakukan dengan menggunakan logistic regression metode enter. Dari analisis tersebut dapat terlihat bahwa ada dua variabel yang secara statistik bermakna meningkatkan risiko terjadinya katarak pada pasien yang berobat di BKMM Kota Mataram, Nusa Tenggara Barat, yaitu pekerjaan dengan $\mathrm{OR}=9,81 \quad(95 \% \mathrm{CI}: 1,85-52,01)$, dan pendidikan dengan $\mathrm{OR}=6,53$ (95\%CI: 1,42-29,92). Hasilnya disajikan pada Tabel 3.

\section{DISKUSI}

Pada analisis multivariat, variabel pekerjaan dan pendidikan memiliki pengaruh terhadap terjadinya katarak, responden yang bekerja di luar gedung $\geq 4$ jam mempunyai risiko sebesar 9,81 kali untuk terjadinya katarak dibandingkan dengan responden yang bekerja $<4$ jam di luar gedung. Sedangkan pendidikan rendah mempunyai risiko meningkatkan katarak sebesar 6,53 kali dibandingkan dengan pendidikan tinggi.

Dari hasil penelitian diketahui bahwa pekerjaaan secara statistik berperan dalam terjadinya katarak, responden yang pekerjaannya $\geq 4$ jam di luar gedung mempunyai risiko lebih tinggi dibandingkan dengan responden pekerjaannya $<4$ jam di luar gedung. Dari wawancara diketahui bahwa ratarata pekerjaan responden yang dilakukan di luar gedung adalah sebagai petani, buruh bangunan, dan pedagang keliling, sedangkan responden yang pekerjaannya di dalam gedung sebagian besar sebagai pembantu rumah tangga, guru dan ibu rumah tangga (tidak bekerja). Rata-rata responden bekerja dari pukul 06.00-17.00. Hasil penelitian ini sejalan dengan penelitian lain yang melaporkan bahwa pekerjaan responden yang berada di luar gedung dapat meningkatkan kematangan katarak sebesar 58,3\% dibandingkan dengan responden pada kelompok pekerja di dalam gedung yaitu sekitar $41,7 \%{ }^{6}$ Dalam suatu penelitian pada tahun 2007 juga melaporkan bahwa prevalensi katarak cukup tinggi pada jenis pekerjaan tertentu, yaitu pegawai sebesar $8,8 \%$ dan petani/nelayan/buruh sebesar $17,8 \%{ }^{4}$

Pekerjaan di luar gedung erat kaitannya dengan paparan sinar matahari. Hasil penelitian ini menunjukkan bahwa paparan sinar matahari secara statistik mempunyai hubungan yang bermakna dengan kejadian katarak. Efek dari radiasi sinar ultraviolet yang berasal dari sinar matahari secara terus menerus dapat menyebabkan terjadinya kekeruhan pada lensa mata dan menyebabkan terjadinya katarak. ${ }^{7}$ Dalam sebuah literatur yang berbeda juga mengungkapkan bahwa penyelidikan epidemiologi menunjukkan di daerah-daerah yang sepanjang tahun selalu ada sinar matahari yang kuat, insiden katarak akan meningkat. ${ }^{8}$ Penelitian yang dilakukan pada tahun 2013 juga menunjukkan bahwa responden pada kelompok yang bertempat tinggal di daerah pantai dengan tingkat kejadian katarak lebih tinggi (61\%) dibanding yang bertempat tinggal di daerah pegunungan yaitu $36 \%{ }^{9}$

Selain pekerjaan, pada penelitian ini juga dijumpaibahwa pendidikan secarastatistikmemiliki pengaruh terhadap terjadinya katarak. Pada analisis multivariat, responden yang berpendidikan rendah mempunyai risiko sebesar 6,53 kali lebih tinggi untuk terjadi katarak dibandingkan dengan responden yang memiliki pendidikan tinggi. Pendidikan rendah dikelompokkan mulai dari tidak sekolah sampai lulus SMP, sedangkan pendidikan tinggi dikelompokkan dari tamat SMA sampai sarjana. Penelitian ini sejalan dengan penelitian lain yang dilakukan pada tahun 2009, yang melaporkan bahwa rendahnya tingkat pendidikan menyebabkan rendahnya sumber daya manusia dan berdampak pada kurangnya pengetahuan masyarakat tentang penyakit khususnya katarak. ${ }^{10}$

Pendidikan rendah pada responden kemungkinan juga berhubungan dengan pekerjaan yang tidak formal, dengan pekerjaan tidak formal yang kemungkinan berpengaruh pada tingkat pendapatan yang diperoleh. Pada penelitian yang berbeda menerangkan bahwa responden yang memiliki pendapatan $<\mathrm{Rp} 500.000 /$ bulan dapat meningkatkan kejadian katarak 2 kali dibandingkan 
dengan responden yang berpendapatan $>\mathrm{Rp}$ 500.000/bulan. Tingkat pendapatan berkaitan dengan pendidikan dan pekerjaan seseorang sehingga menentukan status sosial ekonomi dan berhubungan dengan status kesehatan atau status gizi seseorang. ${ }^{6}$ Selain itu, kemungkinan lain juga pada saat sudah mengalami katarak responden tidak dapat menjangkau biaya operasi mata yang sangat mahal, karena sebagian besar responden memiliki penghasilan per bulan $<R p$ 1.200.000, sehingga masyarakat yang memiliki pendapatan rendah tidak mencari pengobatan untuk penyakit katarak yang dideritanya.

\section{SIMPULAN}

Dalam penelitian ini dijumpai bahwa ada dua variabel yang berperan sebagai faktor risiko terjadinya katarak pada pasien yang berobat di BKMM Kota Mataram Nusa Tenggara Barat yaitu pekerjaan di luar gedung $\geq 4$ jam dan pendidikan rendah.

\section{UCAPAN TERIMA KASIH}

Ucapan terima kasih penulis sampaikan kepada Kepala Dinas Kesehatan Provinsi Nusa Tenggara Barat, khususnya Kepala UPTD-Balai Kesehatan Mata Masyarakat (BKMM) Provinsi NTB dan pihak yang telah membantu dalam kegiatan penelitian ini. Ucapan terima kasih juga penulis sampaikan kepada semua rekan yang membantu terselesainya penelitian ini.

\section{DAFTAR PUSTAKA}

1. Ilyas, S. Katarak. Penerbit Fakultas Kedokteran Universita Idonesia. Jakarta; 2003.

2. Kemenkes RI. Laporan Nasional Riset Kesehatan Dasar 2007. Jakarta: Badan Penelitian dan Pengembangan Kesehatan Departemen Kesehatan Republik Indonesia; 2008.

3. Kemenkes RI. Laporan Nasional Riset Kesehatan Dasar 2013. Jakarta: Badan Penelitian dan Pengembangan Kesehatan Departemen Kesehatan Republik Indonesia; 2013.

4. Kemenkes RI. Hasil Riset Kesehatan Dasar (RISKESDAS) Nusa Tenggara Barat 2007. Mataram: Badan Penelitian dan Pengembangan Kesehatan Departemen Kesehatan Republik Indonesia; 2008.

5. Lwanga SK, Lemeshow, S. Sample size determination in health studies: A practical manual. Geneva: World Health Organization; 1997.

6. Pujiyanto IT. Faktor-faktor Risiko yang Mempengaruhi terhadap Kejadian Katarak Senilis di Kota Semarang tahun 2001 (tesis). Semarang: Pasca Sarjana Departemen Epidemiologi Universitas Diponegoro; 2004.

7. Tana L, Delima, Enny H, Gondhowiharjo T. Katarak pada Petani dan Keluarganya di Kecamatan Teluk Jambe Barat. Media Litbang Kesehatan. 2006: XIV(4); 124-130.

8. Tamsuri A. Klien gangguan mata dan penglihatan. Jakarta: Penerbit Buku Kedokteran EGC; 2004.

9. Wahyudi D, Rinayati, Ambar ED. Hubungan Pekerjaan Tempat Tinggal dengan Tingkat Kematangan Katarak. Prosiding SNST ke-4 Tahun 2013. Fakultas Teknik Universitas Wahid Hasyim; 2013.

10. Hutasoit, H. Prevalensi Kebutaan Akibat Katarak di Kabupaten Tapanuli Selatan tahun 2009 (tesis). Sumatera Utara: Departermen Ilmu Kesehata Mata Fakultas Kedokteran Universitas Sumatera Utara; 2009.

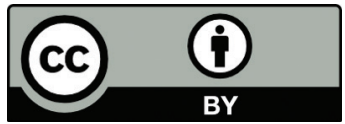

This work is licensed under a Creative Commons Attribution 